\title{
Effect of Chloramphenicol on Reproductive Function in Female Wistar Rats
}

\author{
Oyedeji K.O.*1, Okunlola O. $^{1}$, Oderinde Gbenga ${ }^{2}$ \\ 1. Department of Physiology, College of Medicine and Health Sciences, Afe Babalola University, Ado-Ekiti, Nigeria. \\ 2. Department of Anatomy, College of Medical Sciences, Ahmadu Bello University, Zaria, Nigeria. \\ *Corresponding author's E-mail: sinaoyedeji@yahoo.com
}

Received: 18-05-2021; Revised: 10-11-2021; Accepted: 18-11-2021; Published on: 20-12-2021.

\begin{abstract}
This study was designed to investigate the effect of chloramphenicol on reproductive function in female Wistar rats. Fifteen female rats $(120-160 \mathrm{~g})$ were used for the estrous cycle and histopathological studies. Chloramphenicol $(7.14 \mathrm{mg} / \mathrm{kg})$ was administered orally on daily basis for 21 and 50 days respectively for the estrous cycle and histological studies. Estrous cycle was carried out using the technique of Marcondes et al., histologies of the ovaries and uteri were also carried out. Data were analysed using descriptive statistics and student's t-test at $p=0.05$. Treatment of rats for 21 days with chloramphenicol $(7.14 \mathrm{mg} / \mathrm{kg})$ produced significant $(p<0.05)$ reductions in the proestrous and diestrous phases as well as a significant $(p<0.05)$ increment in the estrous phase of the estrous cycle relative to their respective controls. The histopathological study presented with no visible lesions on the ovaries and uteri, but few endometrial glands have expanded lumen. It can therefore be concluded that chloramphenicol probably has pro-fertility as well as exhibits non-deleterious effects on the reproductive tissues of female Wistar rats.
\end{abstract}

Keywords: Chloramphenicol, Proestrous, Estrous, Ovaries, Rats.

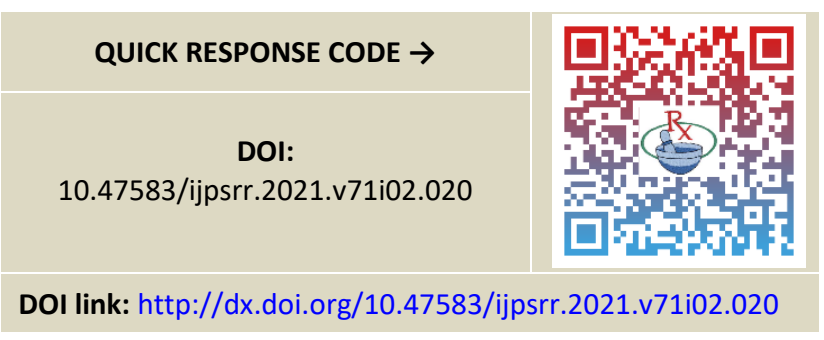

\section{INTRODUCTION}

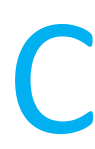

hloramphenicol is a broad spectrum antibiotic, it was first quarantined from bacterium Streptomyces venezualae in the year 1947. It was available by the trade name of Chloromycetin by Parke Davis \& Co. It was prescribed in mass in 1948 in USA following an outburst of enteric fever. In 1949 it was cleared from Federal Food and Drug, since then it has been used and worked upon extensively being a potent inhibitor of protein synthesis ${ }^{1}$. Even being a potent antibiotic with a broad range of spectrum, the use of CAP is limited due to its association with aplastic anaemia ${ }^{2}$ and bone marrow suppression ${ }^{3}$.

The toxic effect of prolong chloramphenicol administration in the livers and kidneys of rats have been reported ${ }^{4}$. Its influence on rat hepatic microsomal components and biomarkers of oxidative stress has been reported ${ }^{5}$. Its pretreatment effect on malathion-induced acute toxicity in rats has been reported ${ }^{6}$. Its toxic effect on erythropoiesis in X-irradiated mice has been reported ${ }^{7}$. Pharmacokinetic interaction between theophylline and chloramphenicol in rats has been reported ${ }^{8}$. Effect of oral administration of chloramphenicol on haematological profile of male Charles Foster rats has also been reported 9 . However, due to scanty information from literature on the effect of chloramphenicol on reproductive parameters in female rats, this study therefore aims at investigating the effect of this antibiotic on these aforementioned parameters in female rats.

\section{MATERIALS AND METHODS}

\section{Experimental Animals}

Adult female rats weighing between $120 \mathrm{~g}-160 \mathrm{~g}$ bred in the Pre-Clinical Animal House of the College of Medicine and Health Sciences, Afe Babalola University were used. They were housed under standard laboratory conditions and had free access to feed and water; they were acclimatized for two weeks to laboratory conditions before the commencement of the experiments. All experiments were carried out in compliance with the recommendations of Afe Babalola University Ethics Committee on guiding principles on care and use of animals.

\section{Drug}

Chloramphenicol capsules (Shandong Xier Kangtai Pharmaceutical Ltd., China) were bought from Danax Pharmacy, Ibadan, Nigeria.

Chloramphenicol (250 mg) was dissolved in $10 \mathrm{ml}$ of distilled water to give a concentration of $25 \mathrm{mg} / \mathrm{ml}$.

The dosage of chloramphenicol used in this study was in accordance with that reported by the manufacturer.

\section{Experimental Design}

\section{Study on Estrous Cycle}

Five matured female rats showing at least three regular 4 - 5 day cycles were used for this study. Vaginal lavages (smears) were examined microscopically every day at a 
constant interval of $4.30-5.30$ p.m. for 21 days before and after treatments with the antibiotic. The smears were classified into one of the phases of the estrous cycle using the Marcondes technique ${ }^{10}$. Vaginal secretion was collected with a plastic pipette filled with $10 \mu \mathrm{L}$ of normal saline ( $\mathrm{NaCl} 0.9 \%$ ) by inserting the tip into the rat's vagina, but not deeply. Vaginal fluid was placed on glass slide. One drop was collected with a clean tip from each rat. Unstained material was observed under a light microscope, without the use of condenser lens, with 10 and $40 \mathrm{x}$ objective lenses. Three types of cells could be recognized: round and nucleated ones are epithelial cells; irregular ones without nucleus are the cornified cells; and the little round ones are the leucocytes. The proportion (preponderance) among them was used for the determination of estrous cycle phases ${ }^{11,12}$. The duration of the estrous cycle was determined. In this study, the experimental animals also served as the control. The first 21 days served as the control days, while the last 21 days served as the treatment days. Each of the 5 rats for this estrous cycle study received $7.14 \mathrm{mg} / \mathrm{kg}$ of chloramphenicol.

\section{Histopathological Study}

In another set of experiment, ten matured female rats divided into two equal groups (five animals per group) received the following treatment of the antibiotic and control (orally) per day for fifty days as follows:

Group I rats received $0.5 \mathrm{ml} / 100 \mathrm{~g}$ of distilled water as the control group.

\section{Group II rats received $7.14 \mathrm{mg} / \mathrm{kg}$ of chloramphenicol.}

On the 51st day, all the rats were sacrificed by an overdose of chloroform. The ovaries and uteri were dissected out, cleaned of fat and immediately fixed in Bouin's fluid.

\section{Histological preparation of tissues}

After weighing the ovaries and uteri, they were immediately fixed in Bouin's fluid for 12 hours and the Bouin's fixative was washed from the samples with $70 \%$ alcohol. The tissues were then cut in slabs of about $0.5 \mathrm{~cm}$ transversely and the tissues were dehydrated by passing through different grades of alcohol: $70 \%$ alcohol for 2 hours, $100 \%$ alcohol for 2 hours, and finally $100 \%$ alcohol for 2 hours. The tissues were then cleared to remove the alcohol, the clearing was done for 6 hours using xylene. The tissues were then infiltrated in molten paraffin wax for 2 hours in an oven at $570 \mathrm{C}$, thereafter the tissues were embedded. Serial sections were cut using rotary microtone at 5 microns $(5 \mu \mathrm{m})$. The satisfactory ribbons were picked up from a water bath $(50-550 C)$ with microscope slides that had been coated on one slide with egg albumin as an adhesive and the slides were dried in an oven. Each section was deparaffinized in xylene for 1 minute before immersed in absolute alcohol for 1 minute and later in descending grades of alcohols for about 30 seconds each to hydrate it. The slides were then rinsed in water and immersed in alcoholic solutions of hematoxylin for about 18 minutes.
The slides were rinsed in water, and then differentiated in $1 \%$ acid alcohol and then put inside a running tap water to blue and then counterstained in alcoholic eosin for 30 seconds and rinsed in water for a few seconds, before being immersed in $70 \%, 90 \%$ and twice in absolute alcohol for 30 seconds each to dehydrate the preparations. The preparations were cleared of alcohol by dripping them in xylene for I minute. Each slide was then cleaned, blotted and mounted with DPX and cover slip, and examined under the microscope. Photomicrographs were taken at $x 40$ and x100 magnifications.

\section{Statistical Analysis}

The mean and standard error of mean (S.E.M.) were calculated for all values. Comparison between the control and the treated group was done using student's t-test. Differences were considered statistically significant at $p<0.05$.

\section{RESULTS}

Treatment of rats for 21 days with chloramphenicol (7.14 $\mathrm{mg} / \mathrm{kg}$ ) produced significant $(\mathrm{p}<0.05)$ reductions in the proestrous and diestrous phases as well as a significant $(p<0.05)$ increment in the estrous phase of the estrous cycle relative to their respective controls (Figure. 1).

Treatment of rats with chloramphenicol $(7.14 \mathrm{mg} / \mathrm{kg})$ for 50 days produced no visible lesions on the ovaries, which is similar to what was observed in the control rats (Plates 1 and 2).

Treatment of rats with chloramphenicol $(7.14 \mathrm{mg} / \mathrm{kg})$ for 50 produced no pathological effects on the uteri but few endometrial glands have expanded lumen, which is similar to what was observed in the control rats (Plates 3 and 4).

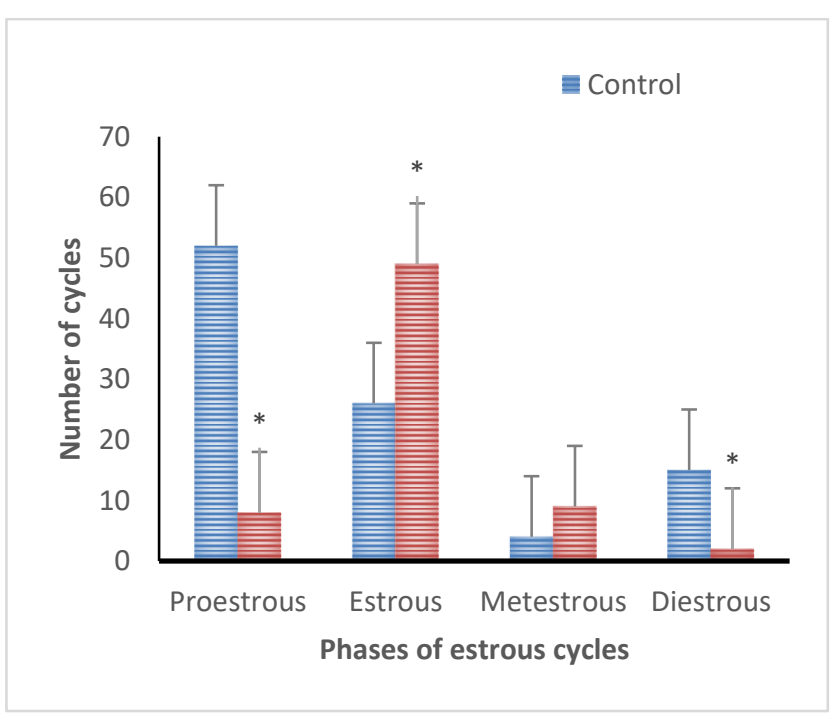

Figure 1: Effect of 21 days treatment with chloramphenicol on estrous cycle $(n=5, * p<0.05)$ 


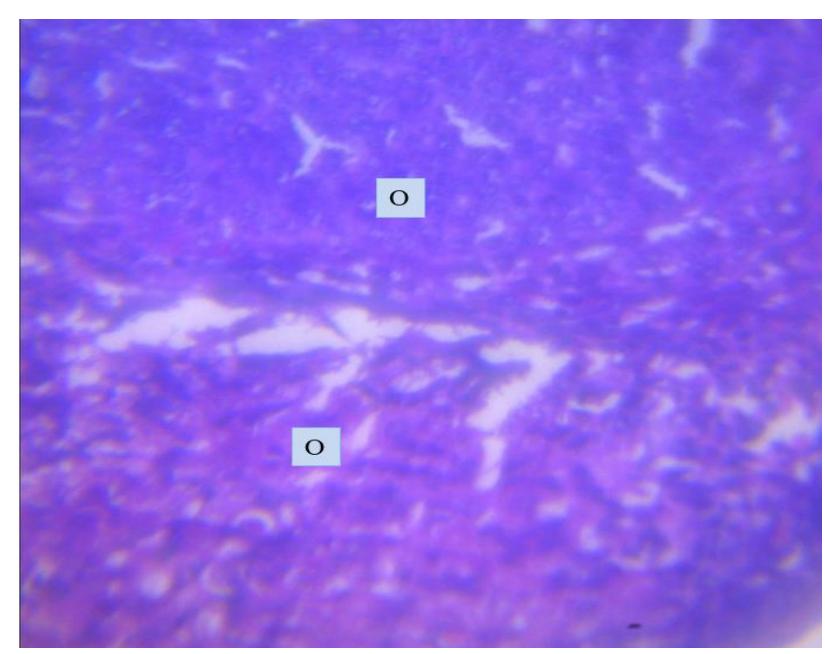

Plate 1: Effect of $0.5 \mathrm{ml} / 100 \mathrm{~g}$ distilled water (control) on the ovary at $\times 400$. Photomicrograph showing a normal ovary (O) with no visible lesions seen.

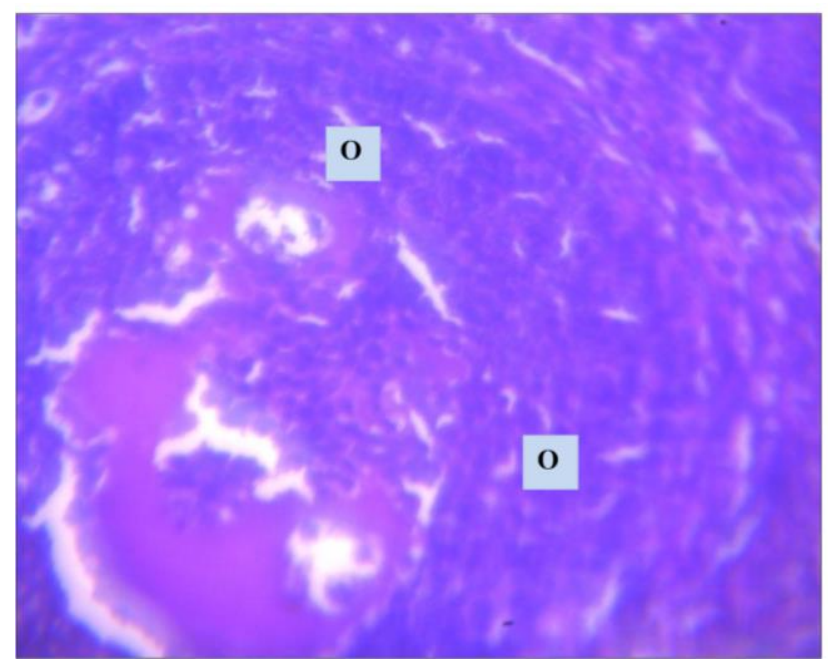

Plate 2: Effect of chloramphenicol $(7.14 \mathrm{mg} / \mathrm{kg})$ on the ovary at $x 400$. Photomicrograph showing an ovary $(0)$ with no pathologic lesions seen.

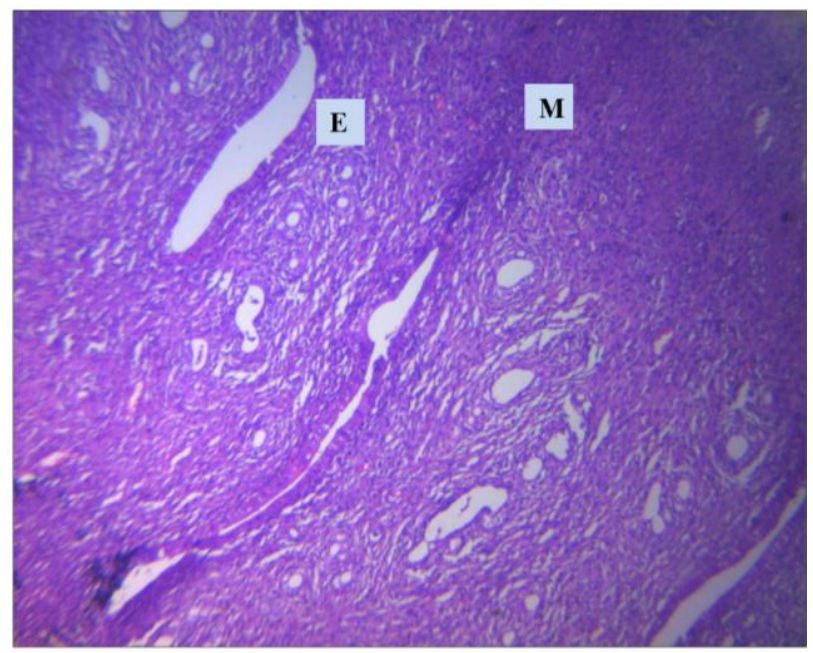

Plate 3: Effect of $0.5 \mathrm{ml} / 100 \mathrm{~g}$ distilled water (control) on the uterus at $\times 400$. Photomicrograph showing normal endometria (E) and myometrium (M) with no visible lesions seen.

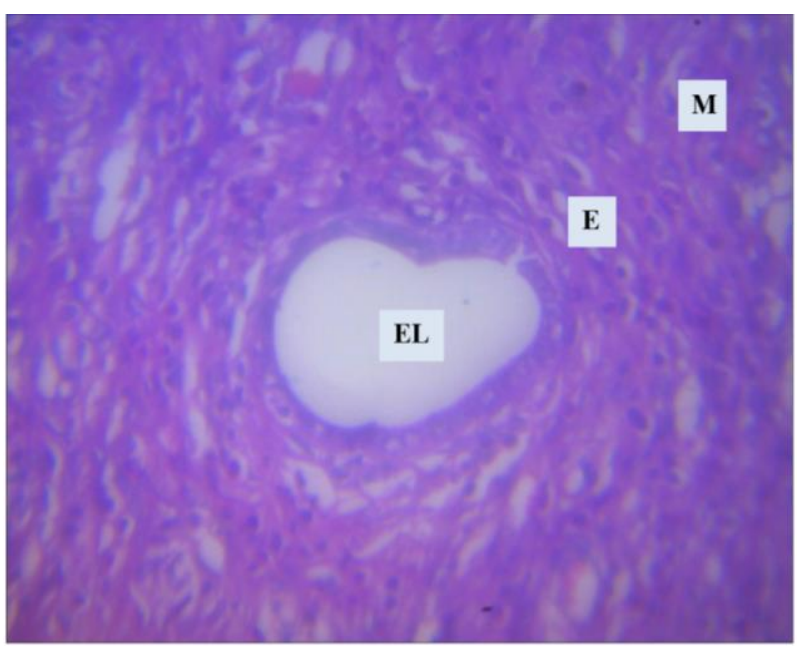

Plate 4: Effect of chloramphenicol $(7.14 \mathrm{mg} / \mathrm{kg})$ on the uterus at $x 400$. Photomicrograph showing endometrial $(E)$ and myometrial $(\mathrm{M})$ layers with no pathologic lesions seen but with expanded lumen (EL) of the endometrial gland.

\section{DISCUSSION}

The estrous cycle study revealed that chloramphenicol caused significant changes in the duration of different phases of the estrous cycle. Contrary report was given by 13 in Portulaca oleracea extracts treated rats. This suggests that the antibiotic caused imbalances of the ovarian and extraovarian hormones, since it has been reported that imbalance in these hormones lead to irregularity in the ovarian functions and duration of the estrous cycle ${ }^{14}$.

Treatment of rats with chloramphenicol caused significant decrease in proestrous phase of the estrous cycle which probably indicates that the maturation of the follicles in the preovulatory phase was hastened leading to maturation of the Graafian follicles. Contrary result was reported by ${ }^{15}$ in alcohol treated rats. Treatment of rats with chloramphenicol caused significant increase in estrous phase of the estrous cycle which suggests the availability of matured Graafian follicles and would lead to ovulation. Similar result was reported by ${ }^{16}$ in alcohol treated rats. In addition, treatment of rats with chloramphenicol caused significant reduction in dietestrous phase of the estrous cycle which suggests an increase in the frequency of ovulation. Similar result was reported by ${ }^{17}$ in amlodipine treated rats.

The ovarian photomicrographs of the chloramphenicol treated rats presented with no visible lesions, which suggests the non-toxic effect of the drug on the ovaries at histological level. Similar results were reported by ${ }^{13}$ in Portulaca oleracea treated rats.

The uterine photomicrographs of the chloramphenicol treated rats presented with no pathologic lesions which probably indicate the non-toxic effect of the drug on the uteri at histological level. Similar results were reported by 18 in Allium sativum extract treated rats. However, the uterine photomicrographs of the chloramphenicol treated rats also presented with few expanded lumen of the endometrial glands which could be due to increase in 
blood flow to the uterine arteries as a result of increased progesterone secretion (from the corpus luteum).

It can therefore be concluded that chloramphenicol probably has pro-fertility as well as exhibits nondeleterious effects on the reproductive tissues of female Wistar rats. However, the effect of this antibiotic on human reproductive function is unknown; nevertheless, considering these findings in animal model, it is recommended that women with infertility problems could take chloramphenicol for infertility therapeutic purpose.

\section{REFERENCES}

1. Cundliffe E, McQuillen K. Bacterial protein synthesis: the effects of antiobiotics. J Mol Biol. 1967; 30: 137 146.

2. Rich ML, Ritterhoff RJ, Hoffman RJ. A fatal case of aplastic anemia following chloramphenicol (chloromycetin) therapy. Ann Inter Med. 1950; 33: $1459-1467$.

3. Ambeker CE, Cheung B, Lee J, Chan LC, Liang R, Kumana CR. Metabolism of chloramphenicol succinate in human bone marrow. Eur J Clin Pharmacol. 2000; 56: 405 - 409 .

4. Saba AB, Ola -Davies O, Oyeyemi MO, Ajala O. The toxic effect of prolonged administration of chloramphenicol on the liver and kidney of rats. Afr J Biomed Res. 2000; 3: 133 - 137.

5. Farombi EO, Adaramoye OA, Emerole GO. Influence of chloramphenicol on rat hepatic microsomal components and biomarkers of oxidative stress: protective role of antioxidants. Pharmacol Toxicol. 2002; 91(3):129-34.

6. Gupta RC, Welsch F, Thornburg JE, Paul BS. Effect of chloramphenicol pretreatment on malathioninduced acute toxicity in the rat. J Toxicol Environ Health. 1983; 11(4-6): 897-905.

7. Vácha J, Pospíšil M, Velčovský V. The toxic effect of chloramphenicol on erythropoiesis in X-irradiated mice. Chemothera. 1981; 27:131-138.
8. Busby $M$, Lesko $\amalg$. Pharmacokinetic interaction between theophylline and chloramphenicol in rats. Drug Metab and Disposit. 1987; 15 (2): 204-206.

9. Shukla $P$, Singh RK. Effect of oral administration of chloramphenicol on hematological profile of male Charles Foster rats. Glob J Medical Research Pharma, Drug Discov, Toxicol and Med. 2013; 13 (4) version 1.0.

10. Marcondes FK, Bianchi FJ, Tanno AP. Determination of the estrous cycle phases of rats: some helpful considerations. Braz J Bio. 2002; 62 (4a): 609 - 614.

11. 11. Long JA, Evans HM. The estrous cycle in the rat and its associated phenomena. Memo Uni Califor. 1922; 6: 1-148.

12. Mandl AM. The phases of the oestrous cycle in the adult white rat. J Exptal Bio. 1951; 28: 576-5 84.

13. Oyedeji KO, Bolarinwa AF. Effects of extracts of Portulaca oleracea on reproductive functions in female albino rats. Afr J Biomed Res. 2010; 13: 213218.

14. Circosta C, Sanogo R, Occhiuto F. Effects of Calotropis proceraon estrous cycle and on estrogenic functionality in rats. Farmaco. 2001; 56: 373-378.

15. Oyedeji KO, Bolarinwa AF, Azeez, AA. Effect of effect of methanolic extract of Vernonia amygdalina on reproductive parameters in male rats. Asian J Pharm Cli Res. 2013; 6 (2): 1-4.

16. Oyedeji KO, Bolarinwa AF, Fashina AM. Effect of alcohol consumption on hematological and reproductive parameters in female albino rats. IOSR J Dent Med Sci. 2013; 3 (5):76-79.

17. Oyedeji KO, Abidoye AO, Alomo TO, Zachariah R. Effect of amlodipine (Calcium channel blocker) on reproductive function in female Wistar rats. J Pharm Sci \& Res. 2019; 11 (12): 3741 - 3744.

18. Raji LO, Fayemi OE, Ameen SA, Jagun AT. The effects of aqueous extract of Allium sativ um (Garlic) on some aspects of reproduction in the female albino rats. Global Vet. 2012; 8 (4): 414-420.

Source of Support: The author(s) received no financial support for the research, authorship, and/or publication of this article.

Conflict of Interest: The author(s) declared no potential conflicts of interest with respect to the research, authorship, and/or publication of this article.

For any question relates to this article, please reach us at: editor@globalresearchonline.net New manuscripts for publication can be submitted at: submit@globalresearchonline.net and submit_ijpsrr@rediffmail.com 